\title{
Differential diagnosis of umbilical polyps and granulomas in children: sonographic and pathologic correlations
}

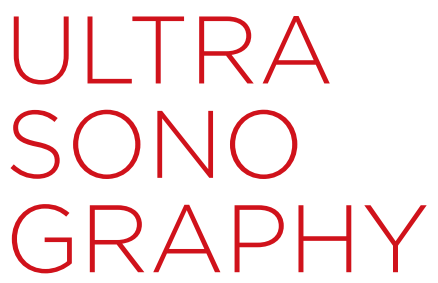

\author{
Dong Hyeon Kim¹, Hee Jung Lee', Jin Young Kim¹, Hye Ra Jung² \\ Departments of ${ }^{1}$ Radiology and ${ }^{2}$ Pathology, Keimyung University Dongsan Hospital, Daegu, \\ Korea
}

\section{ORIGINAL ARTICLE}

https://doi.org/10.14366/usg.20020 pISSN: 2288-5919 - elSSN: 2288-5943 Ultrasonography 2021;40:248-255

Purpose: The sonographic differential diagnosis of umbilical polyps and granulomas in children based on correlations with pathologic findings.

Methods: We retrospectively analyzed the ultrasonographic findings of twenty-two umbilical masses in children that were pathologically confirmed as umbilical polyps or umbilical granulomas by surgery. We analyzed size, depth, echogenicity, internal content, intralesional vascularity, and the presence of unobliterated medial umbilical ligament. Pathologic correlation was performed for all of the umbilical masses.

Results: Twenty-two masses consisted of eight umbilical polyps and fourteen umbilical granulomas. The mean age of the children with umbilical polyps was 30.13 months (range, 2 to 108 months) and it was 1.33 months (range, 0.6 to 3 months) for the children with umbilical granulomas. The average mass sizes were $10.25 \mathrm{~mm}$ (range, 5 to $35 \mathrm{~mm}$ ) for umbilical polyps and $6.21 \mathrm{~mm}$ (range, 3 to $10 \mathrm{~mm}$ ) for umbilical granulomas. The umbilical polyps were manifested as cystic lesions with thick echogenic walls in five patients $(62.5 \%)$, which were associated with the intestinal mucosa (four lesions) and ectopic pancreatic tissue (one lesion) on pathology. Umbilical granulomas were superficially located in $13(92.9 \%)$ and solid in thirteen $(92.9 \%)$, which correlated with prominent granulation tissues on pathology. Seven $(87.5 \%)$ of the eight umbilical granulomas were hypervascular and correlated with neovascularization on pathologic examination.

Conclusion: The umbilical polyps revealed deep-seated, hypovascular nodules with cyst formation surrounded by thick echogenic walls. In contrast, the umbilical granulomas revealed superficially located hypervascular hypoechoic solid nodules in young infants.

Keywords: Umbilical polyp; Umbilical granuloma; Umbilicus; Soft tissue; Ultrasonography

\section{Introduction}

An umbilical polyp is a rare form of omphalomesenteric duct (OMD) remnant consisting of intestinal mucosa at the umbilicus [1-6]. Umbilical polyps are occasionally associated with other OMD anomalies [2,6-8]. The lesion does not regress with the application of silver nitrate, and surgical excision is often recommended due to the possibility of an underlying OMD remnant such as a Meckel

Received: February 7, 2020

Revised: May 20, 2020

Accepted: May 26, 2020

Correspondence to: Hee Jung Lee, MD, Department of Radiology, Keimyung University Dongsan Hospital, 1035 Dalgubeoldaero, Dalseo-gu, Daegu 42601, Korea

Tel. +82-53-258-4106

Fax. +82-53-258-4109

E-mail: hjlee@dsmc.or.kr

This is an Open Access article distributed under the terms of the Creative Commons Attribution NonCommercial License (http://creativecommons.org/ licenses/by-nc/4.0/) which permits unrestricted noncommercial use, distribution, and reproduction in any medium, provided the original work is properly cited.

Copyright (C) 2021 Korean Society of Ultrasound in Medicine (KSUM)

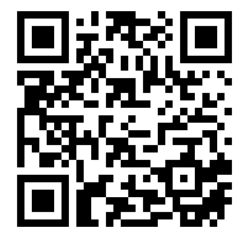

How to cite this article:

Kim DH, Lee HJ, Kim JY, Jung HR. Differential diagnosis of umbilical polyps and granulomas in children: sonographic and pathologic correlations. Ultrasonography. 2021 Apr;40(2):248-255. 
diverticulum, fistula, sinus tract, OMD cyst, or obliterated duct (fibrous cord) $[2,3,6,9]$. The clinical outcomes of umbilical polyps vary from trivial to severe. Therefore, making an accurate diagnosis is important, as it influences treatment.

In contrast, umbilical granulomas arise due to the incomplete epithelialization of the umbilical ring and the overgrowth of granulation tissue. These lesions can be treated with one or two applications of silver nitrate. If the granuloma is too large or if treatment with silver nitrate fails, the lesion may need to be excised [2,10-13].

Although both polyps and granulomas are common umbilical lesions with similar clinical manifestations as small, discharging, reddish umbilical nodules in children, they require different treatments $[14,15]$. Therefore, the differential diagnosis is important to determine the appropriate treatment.

Ultrasonography (US) is the imaging technique used for the initial evaluation of umbilical lesions. US is easily accessible, does not require sedation, does not expose the child to radiation, and provides superior near-field resolution, especially for superficial soft tissue lesions. The US characteristics of umbilical granulomas and umbilical polyps have been described in a few previous studies $[3,11,16]$. However, to our knowledge, no investigations have been conducted regarding the differential diagnosis of umbilical granulomas and umbilical polyps.

The aim of this study was to identify US features that can help to differentiate umbilical polyps and granulomas based on the correlations of these features with pathologic findings.

\section{Materials and Methods}

\section{Study Population}

Institutional review board approval was obtained for this retrospective study, and the requirement for informed consent was waived.

We identified 215 confirmed cases of umbilical masses by searching the pathology database of our institution for completed reports dated between 2010 and 2019. These included 137 cases of pediatric umbilical masses, consisting of $15 \mathrm{OMD}$ remnants (including nine umbilical polyps), 52 umbilical granulomas, and other masses, including 46 umbilical hernias, 11 epidermoid cysts, six urachal remnants, and one hemangioma.

We included patients with either umbilical polyps or umbilical granulomas who had undergone both preoperative US and surgery with pathologic confirmation. Ultimately, 22 children (mean age, 11.8 months; range, 0.6 to 108 months; 17 boys and five girls) were enrolled in this study.

\section{US Analysis}

The US examinations were performed using a high-frequency (12 to $15 \mathrm{MHz}$ ) linear probe. Serial transverse and longitudinal US images of the lesions were evaluated. The US images were retrospectively reviewed by two radiologists who then reached a consensus regarding the images (H.J.L. and D.H.K.; 32 and 2 years of experience, respectively). Both reviewers were blinded to the pathology reports.

The following sonographic features of the umbilical mass were evaluated: (1) size, (2) depth (superficial vs. deep), (3) contents (cystic, solid, or complex), (4) internal echogenicity (anechoic, hypoechoic, isoechoic, or hyperechoic), (5) intralesional vascularity (hypervascular or hypovascular/avascular), and (6) the presence of an unobliterated medial umbilical ligament (MUL) (present or absent). The size was recorded as the largest of the dimensions of length, width, and height. The depth of the mass was classified as superficial when the most superficial portion of the nodule was abutted by the epidermis of the umbilicus and as deep when it was not. A complex mass was defined as the combination of a cyst and a solid lesion, and the level of internal echogenicity was determined via comparison with that of the adjacent muscle. The presence of an unobliterated MUL was defined as the presence of an echogenic mucosal line (Fig. 1).

\section{Pathologic Analysis}

A histologic analysis was performed using hematoxylin and eosin staining. Histologically, umbilical polyps are characterized by glandular structures lined by ectopic intestinal mucosa. Umbilical granulomas predominantly consist of fibroblasts, abundant small vessels, and endothelial and inflammatory cells that lack neural elements. The specimens were retrospectively reviewed by one pathologist (H.R.J., 18 years of experience).

\section{Statistical Analysis}

The statistical analysis was performed using commercial software (SPSS version 25.0 for Windows, IBM Corp., Armonk, NY, USA). To compare the US findings between umbilical granulomas and umbilical polyps, the Mann-Whitney test was used for continuous variables and the Fisher exact test was used for categorical variables. $P$-values $<0.05$ were considered to indicate statistical significance.

\section{Results}

The demographic characteristics of the patients and the US features of the umbilical polyps and umbilical granulomas are summarized in Table 1.

Eight children (mean age, 30.13 months; range, 2 to 108 months; four boys and four girls) were diagnosed with umbilical polyps, 
and 14 children (mean age, 1.33 months; range, 0.6 to 3 months; 13 boys and one girl) were diagnosed with umbilical granulomas. The patients with umbilical granulomas were significantly younger than the patients with umbilical polyps $(P<0.001)$. The umbilical granulomas were predominantly found in boys $(92.3 \%)$, and this difference with regard to sex was statistically significant $(P=0.039)$.

The umbilical polyps had a greater mean size $(10.25 \pm 10.11 \mathrm{~mm})$ than the umbilical granulomas $(6.21 \pm 2.29 \mathrm{~mm})$, but this difference was not statistically significant $(P=0.330)$.

The location of the mass was deep in six $(75 \%)$ of the umbilical polyps, whereas it was superficial in $13(92.9 \%)$ of the umbilical granulomas; this constituted a statistically significant difference ( $P=0.002)$.

The contents of the masses were cystic in five $(62.5 \%)$ of the umbilical polyps and solid in $13(92.9 \%)$ of the umbilical granulomas, a difference that was statistically significant $(P<0.01)$. All of the cystic umbilical polyps exhibited echogenic inner walls; additionally, the cyst walls were associated with intestinal mucosa, including colonic mucosae in two cases (Fig. 2), small intestinal mucosae in two cases, and ectopic pancreatic epithelium in one case (Fig. 3) on the pathologic findings. The pathologic analysis also revealed that of the three (37.5\%) solid umbilical polyps, one contained gastric mucosa (Fig. 4) and two contained fibroepithelial mucosa.

The echogenicity of the umbilical polyps was variable, whereas $78.6 \%$ ( 11 cases) of the umbilical granulomas exhibited hypoechogenicity. These findings regarding echogenicity differed to a statistically significant degree between lesion types $(P<0.001)$.

Fourteen patients underwent color Doppler US. Five (83.3\%) of the six umbilical polyps assessed exhibited hypovascularity
Table 1. Demographic characteristics of patients and ultrasound features of umbilical polyps and umbilical granulomas

\begin{tabular}{|c|c|c|c|}
\hline Characteristic & $\begin{array}{l}\text { Umbilical } \\
\text { polyps }\end{array}$ & $\begin{array}{c}\text { Umbilical } \\
\text { granulomas }\end{array}$ & P-value \\
\hline Total No. of cases & 8 & 14 & \\
\hline Age (month) & $30.13 \pm 41.40$ & $1.33 \pm 0.66$ & $<0.001^{*}$ \\
\hline Sex & & & $0.039^{*}$ \\
\hline Male & 4 & 13 & \\
\hline Female & 4 & 1 & \\
\hline Size $(m m)$ & $10.25 \pm 10.11$ & $6.21 \pm 2.29$ & 0.330 \\
\hline Depth & & & $0.002^{*}$ \\
\hline Superficial & $2(25.0)$ & $13(92.9)$ & \\
\hline Deep & $6(75.0)$ & $1(7.1)$ & \\
\hline Contents & & & $<0.01^{*}$ \\
\hline Cystic & $5(62.5)$ & 0 & \\
\hline Solid & $3(37.5)$ & $13(92.9)$ & \\
\hline Complex & 0 & $1(7.1)$ & \\
\hline Internal echogenicity & & & $<0.001^{*}$ \\
\hline Anechoic & $5(62.5)$ & 0 & \\
\hline Hypoechoic & $1(12.5)$ & $11(78.6)$ & \\
\hline Isoechoic & 0 & $3(21.4)$ & \\
\hline Hyperechoic & $2(25.0)$ & 0 & \\
\hline Intralesional vascularity $(n=14)$ & & & $0.026^{*}$ \\
\hline Hypervascular & $1(16.7)$ & $7(87.5)$ & \\
\hline Hypovascular/avascular & $5(83.3)$ & $1(12.5)$ & \\
\hline $\begin{array}{l}\text { Unobliterated medial umbilical } \\
\text { ligament }\end{array}$ & & & 0.193 \\
\hline Present & $1(12.5)$ & $6(42.9)$ & \\
\hline Absent & $7(87.5)$ & $8(57.1)$ & \\
\hline
\end{tabular}

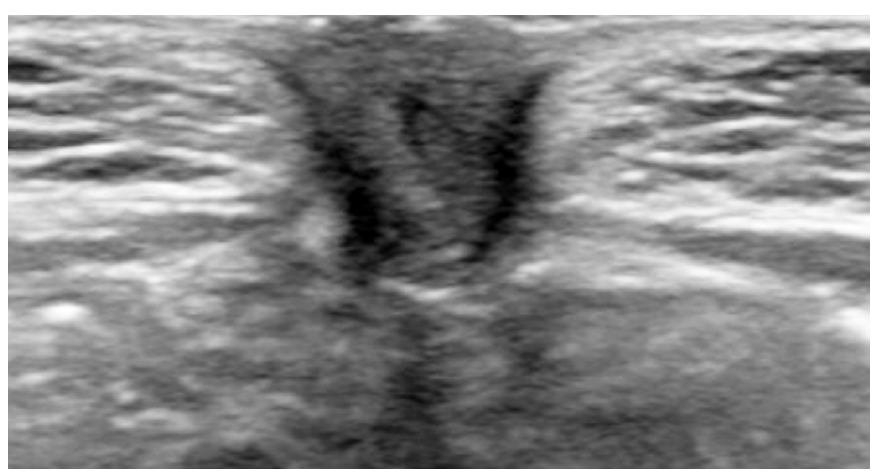

B

Fig. 1. Status of the medial umbilical ligament.

A. The unobliterated medial umbilical ligament is defined by the presence of echogenic mucosal lines (arrows) along the course of both medial umbilical ligaments. B. The image reveals a completely obliterated medial umbilical ligament without echogenic mucosal lines. 


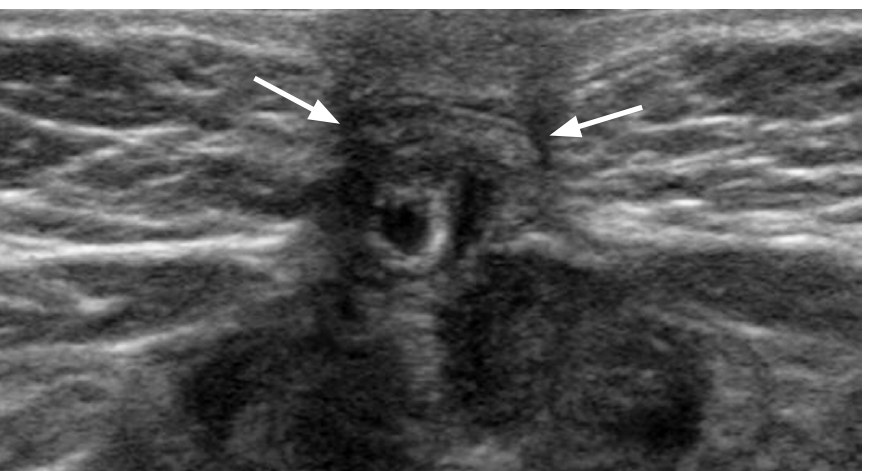

A

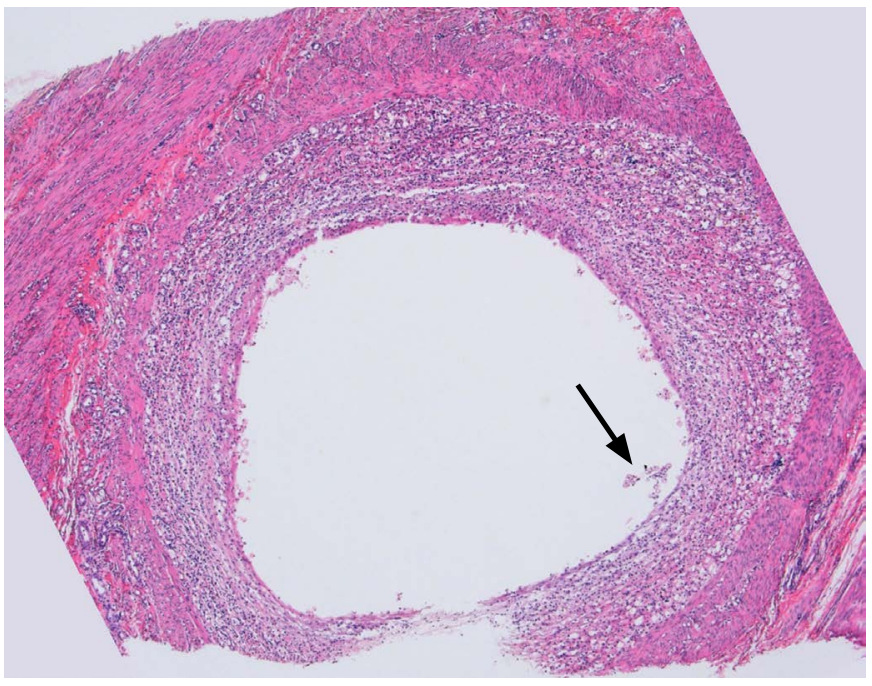

C

or avascularity, whereas seven (87.5\%) of the eight umbilical granulomas exhibited hypervascularity. This difference in intralesional vascularity was statistically significant $(P=0.026)$. The pathologic findings revealed abundant vessels extending from the base of the umbilical granuloma (Fig. 5).

Seven umbilical polyps (87.5\%) and eight umbilical granulomas (57.1\%) demonstrated obliteration of the MUL. The rate of presence of an unobliterated MUL was not statistically different between groups $(P=0.193)$.

\section{Discussion}

The umbilicus is associated with the embryologic development of the gastrointestinal tract, urinary tract $[3,9,16]$, and umbilical vessels (Fig. 6). Notable umbilical masses in the pediatric population include OMD remnants, umbilical granulomas, umbilical hernias, urachal remnants, and benign soft tissue masses, such as epidermoid cysts, hemangiomas, and other benign soft tissue tumors [2]. The pathologically confirmed pediatric umbilical masses at our institution

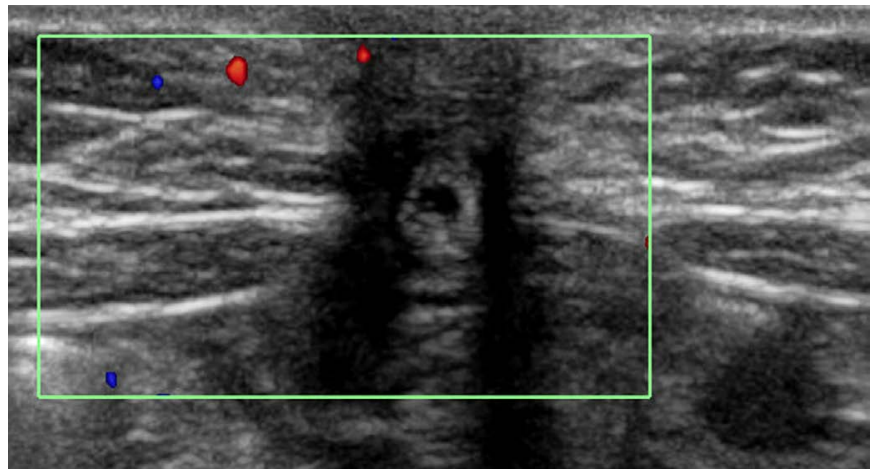

B

Fig. 2. An umbilical polyp in a 3-month-old boy.

A. Transverse ultrasonography shows a 5 -mm-sized cystic lesion with an echogenic inner wall. The lesion shows deep-seated location (arrows) without abutting the epidermis. B. Transverse color Doppler ultrasonography shows hypovascularity of the lesion. C. The pathologic findings show a cyst surrounded by abundant inflammatory cells and a detached intestinal epithelial component (arrow) (H\&E stain, $\times 40)$.

during the study period included, from most to least frequent, 52 umbilical granulomas, 46 umbilical hernias, 15 OMD remnants (including nine umbilical polyps), 11 epidermoid cysts, six urachal remnants, and one hemangioma.

As the placental circulation increases from the fifth to the ninth week of gestation, the OMD usually regresses $[3,16]$. However, a remnant is retained in approximately $1 \%$ to $4 \%$ of infants $[3,5,10,16]$, making the presence of an OMD remnant the most common congenital gastrointestinal anomaly of the umbilicus.

It is necessary to discriminate between umbilical polyps and OMD cysts. An umbilical polyp forms when the OMD mucosa grows outward and associates with the gastric epithelium and/ or small intestinal, colonic, and even islands of pancreatic tissue $[4,5,7,9,16,17]$. In contrast, an OMD cyst is formed when an intermediate portion of the duct retains patent, but both ends are sealed. Both lesions can appear as bright red, fluid-secreting nodules at the umbilicus; any such lesion is often clinically referred to as an umbilical polyp, but an OMD cyst differs in that it has a fluid-filled lumen with a grossly cystic appearance. The histology of umbilical 


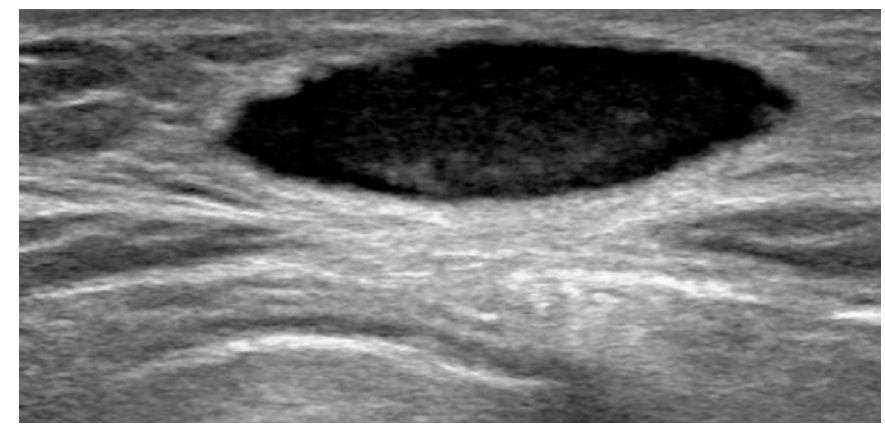

A

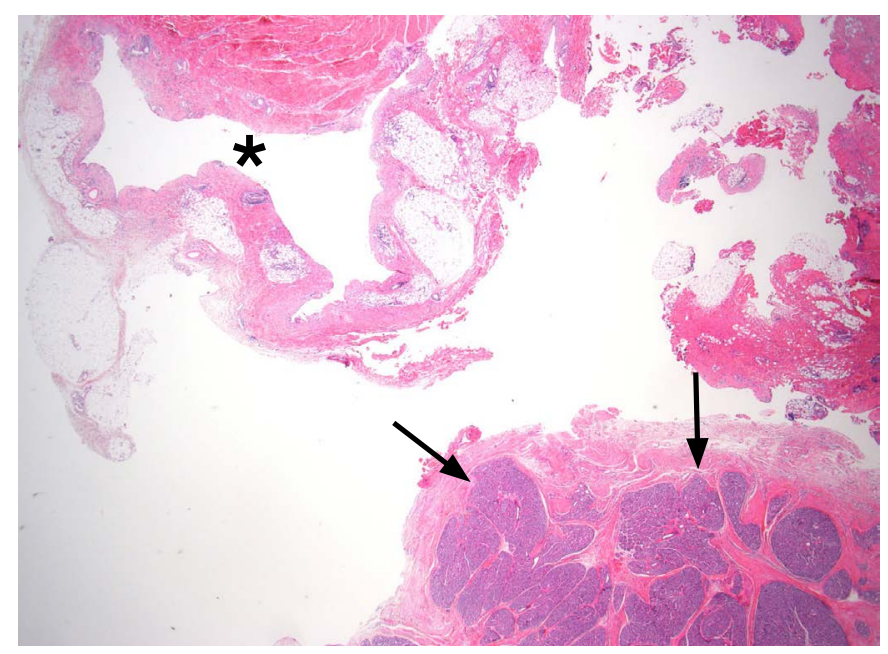

C

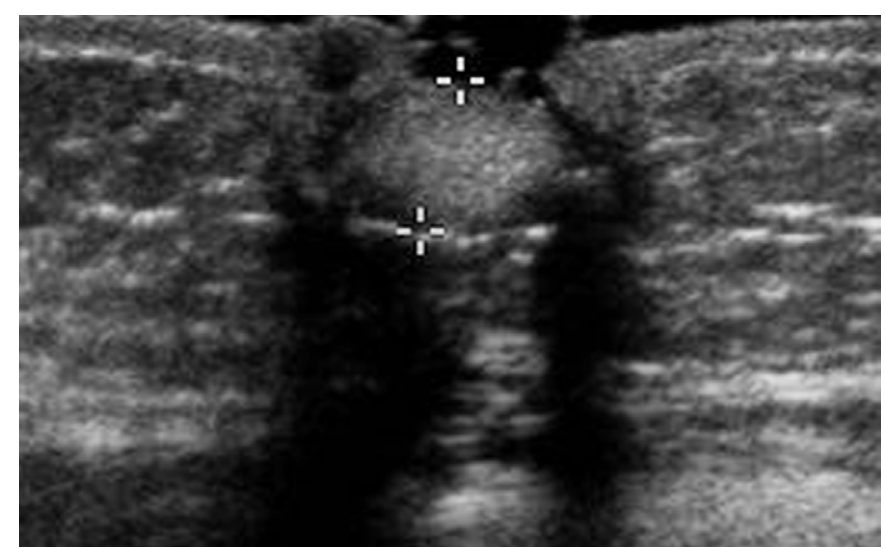

A

Fig. 4. An umbilical polyp in an 11-month-old girl.

A. Transverse ultrasonography shows an 8-mm-sized, superficially located, hyperechoic solid lesion. B. The pathologic findings show glandular structures lined by columnar epithelium (arrow) with apical mucinous globules. This structure resembles gastric mucosal structure (H\&E stain, $\times 40)$.

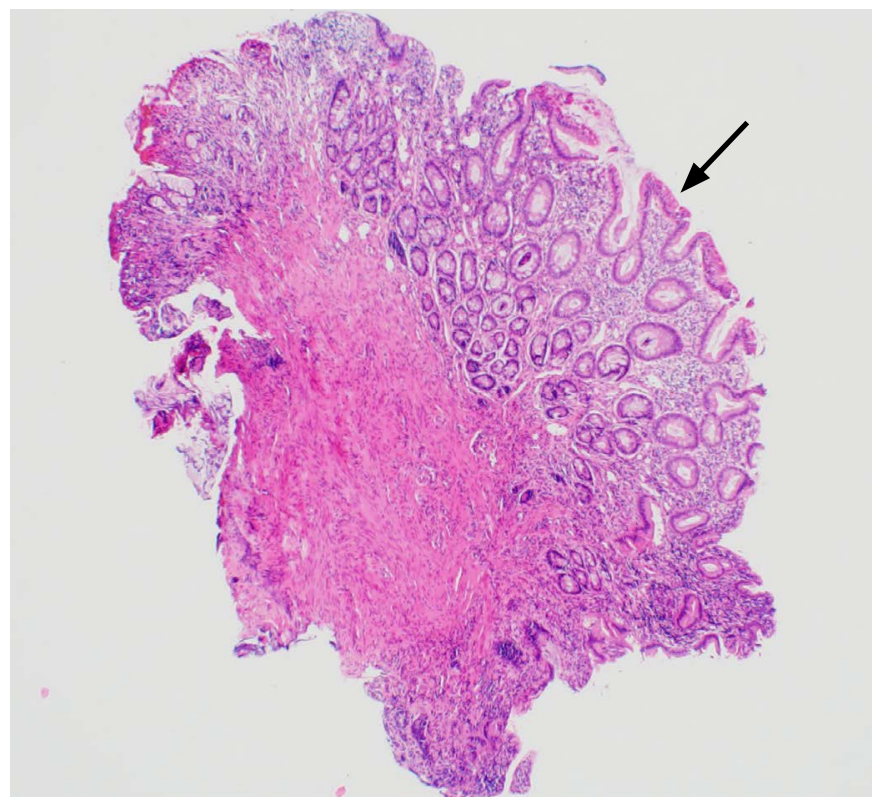

B
A, B. Transverse (A) and longitudinal (B) ultrasonography show a 35-mm-sized, deep-seated, cystic lesion with an echogenic inner wall. C. The pathologic finding reveals cystic space (asterisk). Also, the specimen contains ectopic pancreatic tissues (arrows) (H\&E stain, $\times 12.5)$.

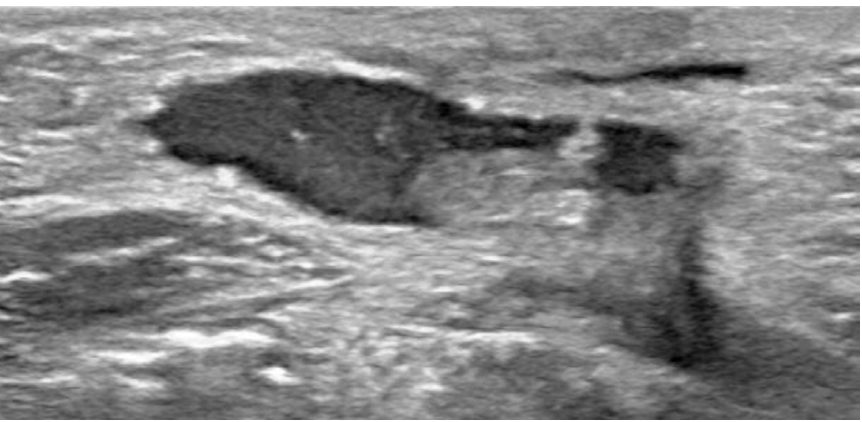

B 


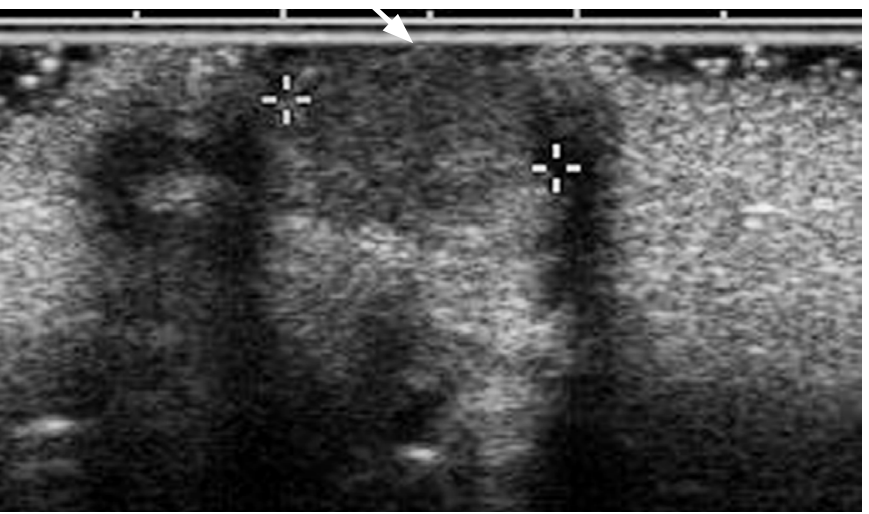

A

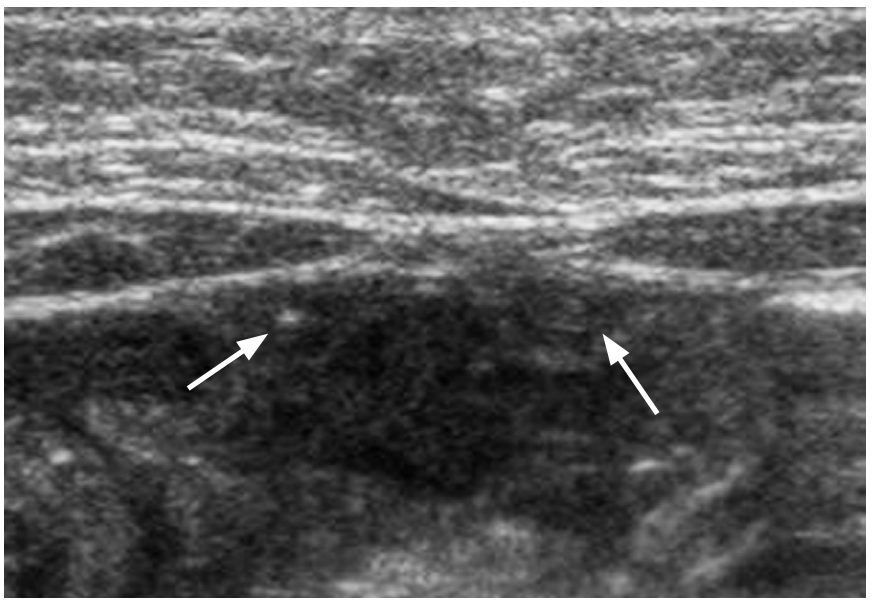

C

Fig. 5. An umbilical granuloma in a 1-month-old boy.

A. Transverse ultrasonography shows a 9.5-mm-sized, hypoechoic solid lesion. The lesion shows superficial location (arrow) with abutting the epidermis. B. Transverse color Doppler ultrasonography shows hypervascularity of the lesion. C. Transverse ultrasonography shows presence of echogenic spots (arrows) along the course of both medial umbilical ligaments. D. The pathologic findings show rich vascular structures (arrows) with surrounding fibrous tissues, correlating well with the sonographic findings (H\&E stain, $\times 12.5$ ).

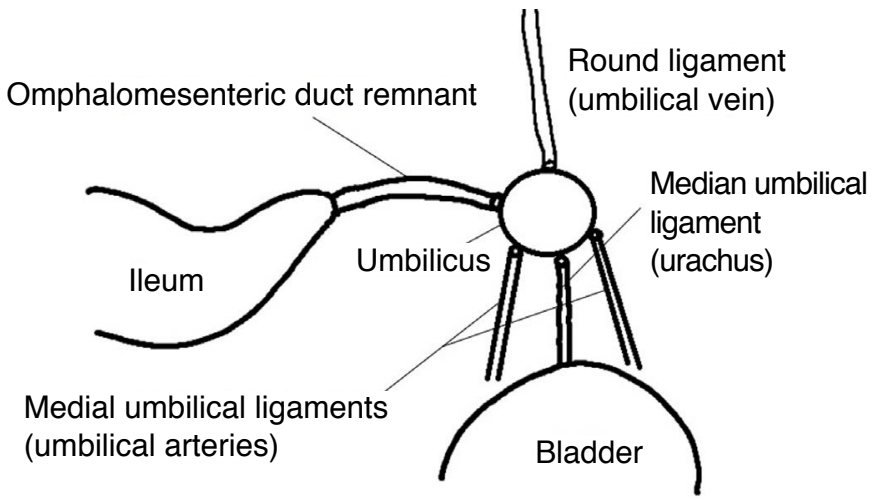

Fig. 6. The illustration of the anatomy of the umbilicus.

polyps and OMD cysts is the same, with both exhibiting a lining of cuboidal or columnar epithelium with gastrointestinal differentiation

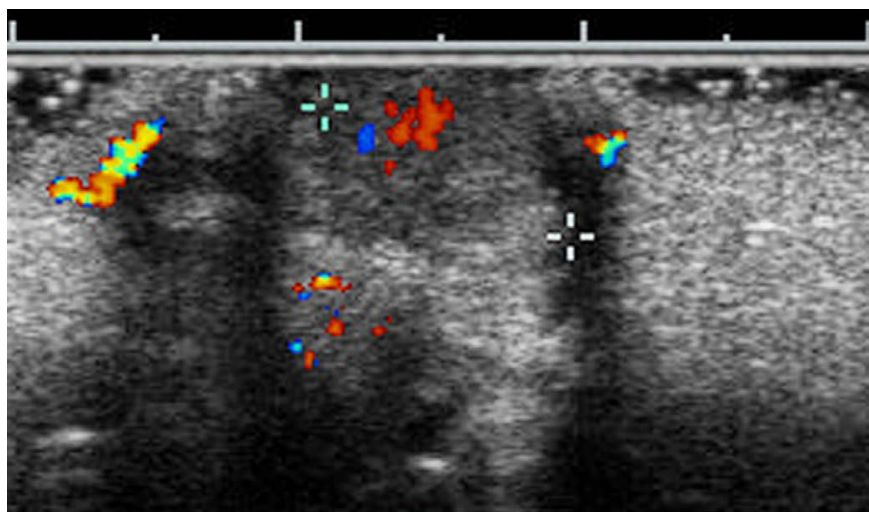

B

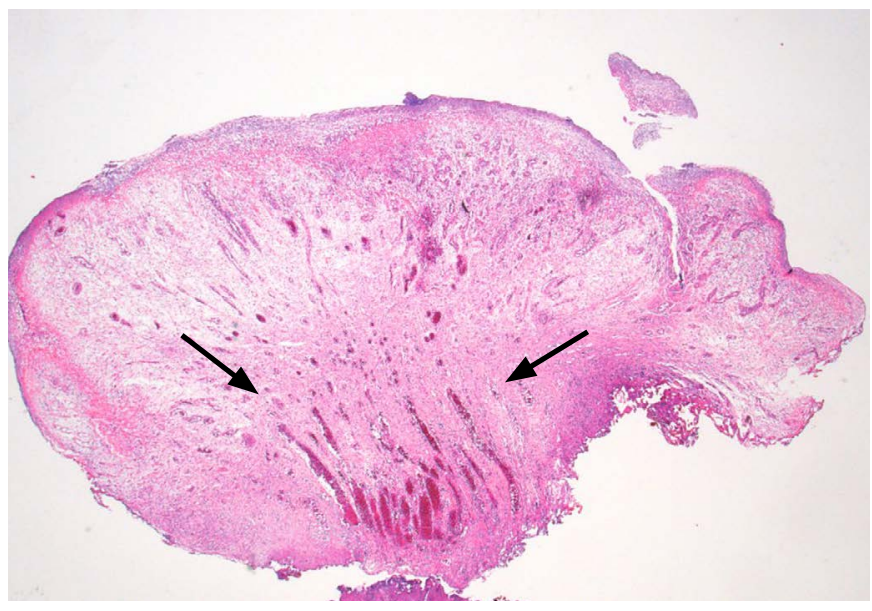

D 
masses. However, a recent review by Pacilli et al. [18] suggested the opposite. In that study, 13 children underwent surgical resection of umbilical polyps, and six children were suspected of having underlying OMD abnormalities. However, no abnormalities were found after abdominal exploration. In addition, the seven children who did not undergo intraperitoneal exploration developed no symptoms over 5.8 years of follow-up. Therefore, the authors suggested that abdominal exploration may not be necessary because the polyp may exist in the absence of other abnormalities. In the present study, none of the umbilical polyps were found to be associated with internal OMD remnants during surgery.

With respect to umbilical polyps, the major differential diagnosis is umbilical granuloma $[8,12,13,18]$. When the fibromuscular ring of the umbilicus closes and the umbilical cord sloughs, the ring is covered anteriorly by skin and posteriorly by peritoneum. After cord detachment, the ring may undergo incomplete epithelialization, causing beefy red granulation tissue to be visible after the first few weeks of life [2]. In the present study, most of the umbilical granulomas abutted the skin (93\%); in such cases, sonographic features can be used to identify the superficial location of the umbilical granuloma. Granulation tissue formation is a normal stage in wound healing and represents the division and migration of endothelial cells to form a rich bed of new capillaries $[2,13,14]$. These pathologic features aligned with the sonographic findings of hypervascular solid nodules in our study, whereas most (83.3\%) of the umbilical polyps exhibited hypovascularity or avascularity. The locations of the masses were also helpful for the differential diagnosis of the two lesions. In $92.9 \%$ of the cases of umbilical granuloma, the mass was superficially located, but umbilical polyps were deeply located in $75 \%$ of cases. Small amounts of serous or serosanguinous discharge may be secreted by both umbilical granulomas and polyps. The secretion may be caused by the unobliterated MUL in umbilical granulomas and by the lining of the intestinal mucosa in umbilical polyps. Although the correlation was not statistically significant, the patients with umbilical polyps exhibited a higher frequency of MUL obliteration than those with granulomas. Importantly, the patients with umbilical polyps were older than those with umbilical granulomas, which may relate to the higher rate of MUL obliteration observed among patients with umbilical polyps. Furthermore, umbilical granulomas predominantly affected male infants to a statistically significant degree.

The differential diagnosis of reddish lesions in the umbilicus and proximal umbilical cord also includes urachal cysts $[12,19]$. These result from the incomplete regression of the allantoic duct (urachus), a second ductal structure in the cord that connects to the embryonic bladder $[1,4,15]$. Urachal remnants are less common than OMD remnants and are usually lined by a single layer of flattened epithelium. They typically present as an infra-umbilical or suprapubic mass, but they occasionally manifest as a red papule at the umbilicus. If located in the proximal umbilical cord, urachal cysts can cause an enlarged or giant cord and are positioned at the inferior surface between the umbilical arteries. A urachal cyst near the umbilicus is rare and may represent an associated sinus or fistula tract along the course of the urachus.

Epidermoid cysts should also be considered in the differential diagnosis. These cysts can contain keratin and desquamated squamous cells. The associated sonographic findings have been reported as onion skin-like or target-like in appearance with varying internal echogenicity. Epidermoid cysts rarely present with a cystic appearance, as in umbilical polyps, or with the hypervascularity observed in umbilical granulomas [20].

In conclusion, umbilical polyps appeared as deep-seated, hypovascular nodules with cystic contents surrounded by thick echogenic walls. In contrast, umbilical granulomas manifested as superficially-located hypervascular solid nodules in young infants.

ORCID: Dong Hyeon Kim: https://orcid.org/0000-0002-4600-8062; Hee Jung Lee: https://orcid.org/0000-0001-7825-9475; Jin Young Kim: https://orcid.org/0000-00016714-8358; Hye Ra Jung: https://orcid.org/0000-0002-1477-6606

\section{Author Contributions}

Conceptualization: Kim DH, Lee HJ. Data acquisition: Kim DH, Lee HJ. Data analysis or interpretation: Kim DH, Lee HJ, Kim JY, Jung HR. Drafting of the manuscript: Kim DH. Critical revision of the manuscript: Kim DH, Lee HJ, Kim JY, Jung HR. Approval of the final version of the manuscript: all authors.

\section{Conflict of Interest}

No potential conflict of interest relevant to this article was reported.

\section{References}

1. DiSantis DJ, Siegel MJ, Katz ME. Simplified approach to umbilical remnant abnormalities. Radiographics 1991;11:59-66.

2. O'Donnell KA, Glick PL, Caty MG. Pediatric umbilical problems. Pediatr Clin North Am 1998;45:791-799.

3. Bagade S, Khanna G. Imaging of omphalomesenteric duct remnants and related pathologies in children. Curr Probl Diagn Radiol 2015;44:246-255.

4. Khati NJ, Enquist EG, Javitt MC. Imaging of the umbilicus and periumbilical region. Radiographics 1998;18:413-431.

5. Abhyankar A, Lander AD. Umbilical disorders. Surgery (Oxf) 2004:22:214-217.

6. Kutin ND, Allen JE, Jewett TC. The umbilical polyp. J Pediatr Surg 1979;14:741-744. 
7. Hsu JW, Tom WL. Omphalomesenteric duct remnants: umbilical versus umbilical cord lesions. Pediatr Dermatol 2011;28:404-407.

8. Swanson DL, Pakzad B. An umbilical polyp in an infant. Cutis 2005;76:233-235.

9. Steck WD, Helwig EB. Cutaneous Remnants of the Omphalomesenteric Duct. Arch Dermatol 1964;90:463-470.

10. Taranath A, Lam A. Ultrasonographic demonstration of a type 1 omphalomesenteric duct remnant. Acta Radiol 2006;47:100-102.

11. Piparsaliya S, Joshi M, Rajput N, Zade P. Patent vitellointestinal duct: a close differential diagnosis of umbilical granuloma: a case report and review of literature. Surg Sci 2011;2:134-136.

12. Pomeranz A. Anomalies, abnormalities, and care of the umbilicus. Pediatr Clin North Am 2004;51:819-827.

13. Fahmy M. Umbilicus and umbilical cord. Cham: Springer, 2018.

14. Karaguzel G, Aldemir H. Umbilical granuloma: modern understanding of etiopathogenesis, diagnosis and management. J Pediatr Neonatal Care 2016;4:00136.

15. Poenaru D. Disorders of the umbilicus in infants and children: a consensus statement of the Canadian Association of Paediatric Surgeons. Paediatr Child Health 2001;6:312-313.

16. Tamilselvan K, Mohan A, Cheslyn-Curtis S, Eisenhut M. Persistent umbilical discharge from an omphalomesenteric duct cyst containing gastric mucosa. Case Rep Pediatr 2012;2012:482185.

17. Lee WT, Tseng HI, Lin JY, Tsai KB, Lu CC. Ectopic pancreatic tissue presenting as an umbilcal mass in a newborn: a case report. Kaohsiung J Med Sci 2005;21:84-87.

18. Pacilli M, Sebire NJ, Maritsi D, Kiely EM, Drake DP, Curry JI, et al. Umbilical polyp in infants and children. Eur J Pediatr Surg 2007; 17:397-399.

19. Parada Villavicencio C, Adam SZ, Nikolaidis P, Yaghmai V, Miller $\mathrm{FH}$. Imaging of the urachus: anomalies, complications, and mimics. Radiographics 2016;36:2049-2063.

20. Kim HK, Kim SM, Lee SH, Racadio JM, Shin MJ. Subcutaneous epidermal inclusion cysts: ultrasound (US) and MR imaging findings. Skeletal Radiol 2011;40:1415-1419. 